\title{
Teaching Tax Law: Undergraduates' Thoughts Regarding the Implementation of Six Thinking Hats Technique
}

\author{
Ufuk Gencel $^{1} \&$ Ilke Evin Gencel ${ }^{2}$ \\ ${ }^{1}$ Canakkale Onsekiz Mart University, Faculty of Economics and Administrative Science, Turkey \\ ${ }^{2}$ Canakkale Onsekiz Mart University,Faculty of Education, Turkey \\ Correspondence: Ilke Evin Gencel, Faculty of Education, Canakkale Onsekiz Mart University, 17100, Canakkale \\ Turkey. Tel: 90-286-217-1303.
}

Received: January 29, 2018

Accepted: February 20, 2018

Online Published: March 2, 2018

doi:10.5430/ijfr.v9n2p31

URL: https://doi.org/10.5430/ijfr.v9n2p31

\begin{abstract}
In learner-centered education, learners are expected not to imitate the knowledge as it is, but to reconstruct it through different perspectives. In this process, creativity is an important factor. In this regard, Six Thinking Hats is a technique suiting constructivist learning, developing multi-perspective thinking, and also supporting decision-making and production skills of students. The aim of the study was to examine opinions of the undergraduates who study faculty of economics and administrative science, regarding the implementation of six thinking hats technique in Tax Law Course. The data was gathered through semi structured interviews, and was analyzed through content-analysis. The participants were generally seen to hold positive thoughts regarding the Six Thinking Hats technique.
\end{abstract}

Keywords: tax law course, teaching tax law, six thinking hats technique

\section{Introduction}

\subsection{Contemporary Tax Law Teaching}

Information societies are in need of individuals who have the ability to solve problems and to bring a different approach. Being able to use a piece of information for problem-solving purposes in different situations has become as important as obtaining the information itself. Identifying a problem encountered in the problem-solving process from distinct point of views in an accurate way is the most important phase in successfully constructing the steps necessary for the solution (Reiter-Palmon and Robinson 2009). For that reason, the problem-solving skill is efficient in easily adapting to ever-changing life conditions as an individual as well as critical in becoming successful in professional life (Evin Gencel, 2017; Vernon \& Hocking, 2014).

The success in finding a solution to a problem encountered in professional life is proportionally linked to the ability of students to acquire the skill to choose the most efficient idea among alternative ideas by adopting different standpoints during their professional education. Indeed, it is very important to bring a different approach on a subject in the departments such as finance, law, economics and management where approaches towards a specific subject can be diverse. Among these, the department of finance is central to the faculties of economics with regards to its curriculum. The department of finance appears to be a hybrid department since it predominantly covers the courses of law, management, economics, public administration and basic finance.

The students in the department of finance are faced with many different problems particularly in relation to the practices of taxation law and legislation during their professional life. Therefore, the cases through which they can apply the knowledge in their education as well as the practices where they can bring a different approach on the subjects through different perspectives will be useful for their professional competence.

Academic studies have emphasized that preparation for the age of digital and information economy calls for the acquisition of these skills (Facione, 2011; Kivunja, 2015b). Tapscott (2009) stated that these skills are vital to the success in both education and career. However, a review of the literature revealed that there is a traditional approach, particularly in higher education, where an instructor provides the information and students listen to the instructor and take notes. This creates a learning environment in which learners are passive (Abeysekera \& Dawson, 2015). Yet, the students at the university level, like those at other educational levels, prefer an environment where they can be 
more active (McCullough \& Munro, 2016). On the other hand, social constructivist approach to learning highlights the need for an environment where students effectively construct knowledge in an interactive way of learning and where the students, even at the university level, can be active and interact with each other (Huxham, 2005; Kuh et al., 2010). Indeed, McCullogh and Munro (2016) expressed that the students of the department of finance found the interactive learning environment, which is maintained by active learning tasks, more efficient and lasting.

The course of tax law is one of the most important courses with the highest course credit in the curriculum of the department of finance. In teaching the course of tax law, traditional practices for implementing the curriculum should be replaced by the practices underlying a contemporary, authentic and activity-based curriculum. This is a necessity given that the traditional methods for teaching tax is simply a transfer of knowledge and have a poor applicability to real-life situations. On the other hand, tax law is a field in a constant change, like engineering and medicine fields.

When teaching the course of tax law is restricted with traditional methods such as lecture, the rapidly changing information on tax legislation may not be taught in effective way. Therefore, learning how to approach an issue from different points of view, developing the skill of problem solving and being active in teaching-learning process are essential (Blissenden \& Newlyn, 2012). In this regard, the components to be considered in developing a curriculum can be listed as follows: teaching for thinking, teaching of thinking, teaching with thinking, and teaching about thinking (Brady \& Kennedy, 2003).

The application of contemporary curriculum will allow the development of different standpoints for the situations that require the implementation of tax laws. For instance, although it is necessary for one to have knowledge of a change in the taxation of pension contributions by the government, such knowledge might be a piece of knowledge to be amended in a short period of time. Instead, it appears to be more important that approaching and discussing the issue from different points of view, and using efficient methods for students, a student develops an understanding of government policies for the taxation of certain sectors, rather than the pension taxation system. In all these processes, the focus should be placed on critical thinking (Blissenden \& Newlyn, 2012). Indeed, it has been argued that being endowed with the skill of critical thinking in professional life is more valuable than having the information itself and that employers place importance on certain characteristics such as efficient communication, conflict resolution, understanding different aspects of perspective, and creativity (Geissler, Edison, \& Wayland, 2012; Wooldridge, 2008).

\subsection{The Six Thinking Hats Technique}

The six thinking hats technique is a contemporary teaching technique aimed at the acquisition of all these skills. The six thinking hats technique refers to a parallel thinking technique that represents every different way of thinking with a colored hat and is used in the discussions, which are intended to find the most appropriate solution for a problem or to understand an issue (De Bono 1985). Wearing hats is a metaphor, symbolizing different points of view. In this technique, each of the participants is expected to think and generate ideas about an issue/a situation by coming up with arguments required by his or her own hat and differently from others. In this way, one can elaborate on the issue. Contrary to a single, confusing effort to understand an issue, this technique individually addresses an issue from each different point of view and thus eliminates any confusion (De Bono, 1992a; 1992c; 1992d)

The white hat is neutral. The one wearing it is concerned with objective facts. He or she is expected to provide objective data without making any judgment or showing any feeling. Thus, the issue becomes clearer for everyone (De Bono, 1985; 1992d). The white hat should focus on the following questions: "What information do we have about this issue? Is there sufficient information? What information do we need? Which questions should we ask to get relevant information? Are the available data reliable and valid? Where does the information come from?" (Kivunja, 2015b). The red hat brings feelings like fear, doubt, joy, frustration, gut instinct to a discussion. While there is often an attempt in a formal discussion to move away from feelings, embracing such feelings is considered as a unique part of the six thinking hats technique. Since the involvement of feelings in the logic of thinking developed during a discussion is regarded important in creating multiple points of view (De Bono, 1985; 1992b; 1995). Accordingly, the following questions can be asked: How would you feel if you get involved in this? What are the points that you did not like about the issue or the solution? Which points did you find interesting, exciting?" (Kivunja, 2015b).

The black hat serves as an early warning system. This hat is expected to be aware of the risks and to scrutinize whether the ideas suggested by others would present any drawbacks in terms of available resources, legal, social, ethical values or not (De Bono, 1992a; 1992c). It seeks to answer the following questions: "What are the evidences? Are the suggestions fair, reasonable and applicable? What could prevent the operation of the plan? What are the drawbacks of the suggestions? What threats could be expected?" In this way, the students who came up with any 
suggestion are asked to justify the suggestion. One wearing the black hat should take into consideration the effects of the suggestions or the opinions on the values of others (De Bono, 1992b; Kivunja, 2015b).

Unlike the black hat, the yellow hat embraces a constructive and positive thinking towards an issue. One wearing the yellow hat is expected to focus on the positive outcomes of the ideas, which are proposed from an optimistic point of view. However, due to an unrealistic and excessive optimistic attitude, the decisions made in the end of a discussion may be unreasonable. The yellow hat seeks to determine the value in the opinions proposed (De Bono, 1992c). It should focus on the explicit and implicit benefits of the opinions or suggestions and the questions such as "What are the benefits to the group, class, school or community? How can we come to conclusion based on the available information? What could we do to make the situation better?" (Kivunja, 2015a).

The green hat is expected to generate creative ideas, options, alternatives, unique solutions. It can deliver the ideas that do not occur to or are not possibly shared by many people. Since lateral or synthetic thinking triggers creativity. In other words, the green hat can also produce "kind of crazy ideas." To do so, students should learn the brain-storming strategies (De Bono, 1995; Petty, 2009).

The blue hat represents thinking about thinking and controlling the whole process. It ensures that one does not act against the ways of thinking indicated by the hats during a discussion. It can be called the mentor or the leader of a discussion. The blue hat determines and announces the time when the participants switch between different hats. As the blue hat is a permanent role, anyone can be willing to wear it at the beginning of a discussion. One wearing the blue hat is asked to form a summary, a conclusion or a solution related to the discussion. Following that, the solutions can be accepted, implemented or reconsidered (De Bono, 1992b). Whereas the other hats focus on a specific issue or problem, the blue hat should think in a metacognitive way. Since it is expected to think about the thinking process of others and to act as a leader in solving the problem or in explaining the issue (De Bono, 1992b; Kivunja, 2015b).

The six thinking hats technique improves the problem-solving skill as well as thinking creatively and from different perspectives. As one switches on to another type of thinking required by a hat in a different colour and develops different perspectives towards the issue or the problem. No hat is superior to the other; each has the same potential to contribute to gaining an understanding of the issue as well as solving the problem. Costa and Kallick (2000) stated that having participated in a sufficient number of practices, individuals start to employ such way of thinking out of habit in the process of making decisions and solving problems in their life. Indeed, it is necessary to analyze the effects of this technique, which facilitates learning and decision-making process (Geissler, Edison, and Wayland 2012; Hodge \& Ozag, 2007), in an experimental study and to reveal the opinions of the participants in relation to the implementation of the technique (Vernon \& Hocking, 2014).

That being said, this study aims to apply the six thinking hats technique in the course of tax law, to analyze the opinions of the students in relation to the practice, and to determine whether it is an effective alternative for teaching tax law or not.

\section{Method}

This study applied the six thinking hats technique at the course of Tax Law and analyzed the opinions of the students in relation to the application of the technique. In this respect, the study was performed in a phenomenological research design, which is one of the qualitative research methods. The phenomenological research design seeks to reveal and interpret the views, opinions, experiences and feelings of individuals about a phenomenon. For this purpose, the process generally involves observation, interview and document review (Creswell, 2013).

\subsection{Participants}

This study employed convenience sampling, which is one of the purposeful sampling methods. In line with convenience sampling, a researcher selects a population because of its convenient accessibility and proximity. The participants of the study were 50 undergraduates enrolled in the course of Tax Law and studying in the Department of Finance, the Faculty of Economics and Administrative Sciences, in a state university located in the western part of Turkey.

\subsection{Data Collection}

The data of the study were obtained by means of 'semi-structured interview' forms. The forms were prepared based on a review of the literature and the opinions of 3 experts in the field of educational sciences. There were five questions to determine the opinions on the application of the six thinking hats technique as well as some follow-up questions at the end in the forms. These questions made it possible to reach a deeper understanding (Esterberg 2002). 
The interviews, which lasted about 20 minutes, were recorded and transcribed. Then, to obtain participant confirmation, the students interviewed were asked to check the transcriptions. The questions in the data collection tool were as follows:

1. What do you think about the application of the six thinking hats technique?

The follow-up questions: what were the strengths of the application, what were the drawbacks, what were the challenges?

2. Do you think that the application of the six thinking hats technique was useful to you? If so, how?

The follow-up questions: Could you please evaluate it in terms of information, feeling and relationships with friends?

3. Could you please tell about an experience you are impressed with, a thing that you remember about the application of the six thinking hats technique?

4. Would you prefer the six thinking hats technique to be applied in other courses?

The follow-up question: In your opinion, which courses are suitable for the application and which are not?

5. Is there anything that you would like to add about the application of the six thinking hats technique in teaching tax law?

The follow-up question: How can it be improved?

\subsection{Data Analysis}

The data analysis was conducted by means of inductive content analysis, which is a content analysis based on coding. In the process of data analysis, the audio records were first transcribed, then coded by the researchers individually, and the themes were formed.

\subsection{Validity and Reliability}

The inter-coder reliability (consistency) in the study was calculated based on the formula of "Reliability= Number of Agreements/Total Number of Agreements + Disagreements) x 100 (Miles \& Huberman, 1994) and the compliance was found to be $81 \%$. For the external reliability of the study (confirmability), the processes were explained in detail. The audio records and the notes and encodings on the data collection forms, which were transcribed, are stored by the researchers for possible verification. For the internal validity (credibility), the categorizations in the content analysis were ensured to be wide enough to include the relevant concepts and narrow enough to exclude the unrelated ones. The participant confirmations were obtained; the samples from the participant statements were provided without any change, in direct quotations. For the external validity, the process of conducting the study was elaborated in the sections of research design, participants, data collection, data analysis; the categories were determined in line with the theoretical structure.

\section{Findings}

The themes, identified from the interviews with the participants as result of the content analysis, were Permanence, Usage in Everyday Life, Perspective, Difficulty, Usage in Other Courses and Empathy.

The participants stated that the application of the six thinking hats technique in the course of Tax Law achieve permanent learning. They said that the subjects in the course can be learnt or recalled without any extra practice or memorization. The sample statements are provided below.

"The information given through lecture in a course are not recalled. This way of learning has made the learnt information permanent." (P43)

"This was the first time that I had a course with the six thinking hats technique and I enjoyed it. We evaluated the issue of tax laws. I can fully recall the subject of tax penalties. I do not think that I will forget about it thanks to this activity. It was very effective for me. In fact, I gave complete answers to the relevant questions in the exam." (P30)

"We realized that we recalled all the subjects in the course when we talked about the practice with our friends, even a few weeks after the course." (P1)

The participants stated that they use different ways of thinking applied in the six thinking hats technique in their everyday life as well. They remarked that they evaluate the possibilities by recalling the activities in the courses particularly in situations where they are required to make decisions. Below are the sample statements. 
"We made plans to visit my hometown with one of my friends next week after the midterm. We were going to Izmir. Before deciding on, we used the six thinking hats technique. We decided not to go to Izmir. Instead, we visited another city and postponed the trip for Izmir (city) for a month." (P-17)

"I have never been able to notice my innovative aspect, since I was always doing and enjoying the things that I knew. This practice made me realize that, and now, I employ these different ways of thinking not only during the course but also in my everyday life." (P-9)

"I tend to see things pessimistically and emotionally. Thanks to the six thinking hats technique, I am now making more reasonable decisions and analyzing situations better." (P-10)

"I automatically imagine, while watching TV shows and news, myself in different hats. It has become a part of my life, and I am enjoying it." (P41)

"I will be certainly faced with different situations, as is now, in the future and I will evaluate them from different perspectives thanks to this technique." (P-14)

The participants stated that they realized that the six thinking hats technique has an impact on their perspectives and it is useful to look things from different perspectives. They considered the change in themselves as a positive change. Some of the statements related to this theme are given below.

"Before that, there were only two different ways of looking at things for me, like the empty and full side of a cup. Through the six thinking hats, I understood that having a critical, neutral, emotional, and innovative look would be useful too and leads to new conclusions. I discovered my characteristics such as analyzing and interpreting situations." (P-22)

"By means of teaching through the six thinking hats, one learns that he or she should not look the world from a single window. We can come to realize that approaching an issue pessimistically would be scientifically very useful too. It teaches one to bring forward not only the things in his or her mind but also those that he or she cannot think about. I find it very useful." (P-19)

"I realized that looking at things from a single point of view could mislead us and that looking from different perspectives would lead to more useful outcomes." $(P-37)$

"I thought that it would be wrong to look always from a scientific point of view and that having an emotional approach may be beneficial from time to time" (P-22)

"To be honest, I used to be a pessimistic person. Yet, having discovered this practice, I can now look at things from other perspectives.” (P-13)

"My friends wearing the hats about the issue of tax exemptions came up with different ideas. Although my opinion was different, I got new ideas after reviewing the statements of my friends. " (P-46)

Some participants expressed that they had difficulty in and experienced some challenges during the application of the six thinking hats technique. The sample statements are provided below.

"In the course, I, along with six of my friends, wore hats, and my colour was yellow. In other words, I was supposed to positively approach the issues. Although I had a same perspective towards the issue, it was challenging at that moment to evaluate the opinions of the other hats on the issue from different perspectives and to put together the ideas of my friends with mine. Two minutes after, when I sat down at my desk, many different ideas came into my mind, and I reproached myself for not having said those ideas and for not having been able to articulate my own ideas. In my opinion, the reason for such experience is that I am not accustomed to think differently; what's worse, I was incapable of even telling what I thought. I hope that we can overcome these unfavourable behaviors through such practices." (P-10)

"I think that it is not easy for those who are accustomed to look at things from a single perspective to employ this technique. All in all, it is a group activity...” (P-1)

"People have their own truths and it is a bit hard to agree to the idea of another. This is one of the most difficult things for me during the practices" (P-25)

"I was worried about the hat that I would be assigned to. To be honest, it was challenging for me to be stressed about thinking what ideas I could come up with while wearing the hat that I was assigned to." (P-39) 
"I felt as if my mind went blank when I was assigned to the hat which was the very opposite to my perspective. I was not able to think for a moment and I was very surprised at myself. Then, I started to get used to it and came up with ideas. It was difficult but exciting." $\quad(P-40)$

"It would be easier to apply it if we learnt about it as a kid. Now, it takes a while to get used to it" (P-6)

"It is very difficult for a single person to wear six hats at the same distance." (P-33)

The participants reported that the use of the six thinking hats technique in other courses would be useful. The sample statements are given below.

"Many courses teach us to always act in the same way. As a matter of fact, it can be said that we scarcely think about anything. I think we should apply it to other courses." (P-27)

"Due to the department that we study, the course subjects are not the subjects about which we can inquire much. The subjects include laws and rules. Yet, given that we were able to have such a different perspective in the course of Tax Law, we should stop always embracing the same idea and acting as if we had blinders on" (P-12)

"We are in an educational system based on memorization rather than learning, which prevents reasonable thinking. In point of fact, it prevents not only reasonable thinking but also thinking itself. I think that it should be included to our educational system in no time and applied to every course, if possible." (P-5).

The following statements of some participants implied that the application of the six thinking hats developed empathy.

"Now I realize that I used to look at things emotionally like the red hat and pessimistically like the black hat. I could not be objective. When I got a bad mark, I used to think that the lecturer did not like me and gave this mark on purpose. When I broke up with my girlfriend, I always shifted the blame on her. The greatest contribution of this technique to me is that it improved my feeling of "empathy" (P-36)

"This technique eliminates any bias. It teaches one to think like the other, instead of judging him or her. This thinking technique can enable the individuals in the society to value each other more." (P-26).

"As if it opens your mind and enables you to see the minds of others. You start to understand them better. You know that you are supposed to think as required by the hat. Even if you do not agree, you understand him or her. You think that if I was the one wearing the hat, I would say the same thing." (P20)

\section{Discussion and Conclusion}

This study concluded that the students in the department of Finance believed that the six thinking hats technique applied at the course of Tax Law positively has contributed to their academic as well as personal development, but they experienced some difficulties in performing the practice. The course of Tax Law is a course requiring students to learn various laws, regulations and principles and sometimes to memorize them. Education on tax law is essential for both the students in the department of finance and those in other departments related to economics (Chetty \& Saez, 2013). On the other hand, as education on tax law is considered as complex and challenging, students may have difficulty in ensuring the permanence of the information they learn. O'Prey and Shephard (2014) stated that being an active student in the education on finance has a positive impact on the retention of information and the perspective towards learning. Mauer and Lee (2011) argued that there is no such thing as the best method in teaching finance and tax, but there are studies showing that the methods where students are active are effective. In the present study, the participants reported that the information that they learn through the six thinking hats technique are permanent. Geissler, Edison and Wayland (2012) also stated that the six thinking hats technique prevents students from acting passive and avoids daydreaming during the course. Also, this technique enables each student in the classroom to express themselves. Eldeen and Maher (2016) argued that thinking based on the six hats is effective both in creativity and in ensuring a permanent academic success.

It was found that the participants started to employ the six thinking hats technique in their everyday life and to look at situations from different perspectives. Gudmunson et al. (2015) indicated that the use of the methods, where students are active, in teaching finance improves their learning skills as well as their ability to make decisions. Kivunja (2015c) emphasized that this technique is effective in acquiring some skills such as problem-solving skill. Given that thinking based the six hats has a positive effect on creative and critical thinking, it can be argued that the finding of this study is consistent with the literature. It is expected that the individuals, having learnt to look at issues and situations from every different perspective, apply it to their daily life. Indeed, thinking based on the six hats positively affects the ability of self-expression too, which is an acquisition that can be seen in everyday life (Schellens et al., 2009). Geisler, Edison and Wayland (2012) also obtained similar findings. 
The present study found that another acquisition of the technique is empathy, evident both in the courses and in the daily life, which is similar to the findings of Miglieti (2002). Some of the participants expressed that they had difficulty in group activities. It is also present in the literature that group activities may be challenging for both instructors and students from time to time (Geissler, Edison, \& Wayland, 2012). In this sense, it is not unusual that they had difficulty in practicing the six thinking hats technique. To overcome such difficulties, there should be a sense of teamwork in the classroom. Peer learning and assessment is useful in this process. Also, clarifying the expectations from students in a group work may be useful in reducing their stress (Brutus \& Donia, 2010; Graeff, 2010).

As can be seen, in the present study, the application of six thinking hats technique achieved learning acquisitions in the course of tax law, which incorporates both theoretical and complicated information, as well as other acquisitions. In this regard, it can be stated that it can be considered as an alternative way in teaching finance and tax law. However, it is necessary to perform an experimental study and to take into consideration its findings. Further studies with a control group in an experimental design may be performed to obtain quantitative data on the application of the technique, which can contribute to the literature. Moreover, given that technology has become a part of every area of life, technology-supported learning environments incorporating the six thinking hats technique can be used in teaching finance and tax as well.

This study obtained the opinions of the students regarding the application of the six thinking hats technique. Further studies may focus on analyzing the opinions of the instructors who designed the application. The present study concluded that the opinions of the students regarding the application of the six thinking hats technique in the course of tax law were positive. Also, this study will potentially contribute to other studies on the formation of instructional designs based on student-activity in teaching finance and tax for new interdisciplinary studies.

\section{References}

Abeysekara, L., \& Dawson, P. (2015). Motivation and cognitive load in the flipped classroom: definition, rationale and a call for research. Higher Education Research \& Development, 34(1), 1-14. https://doi.org/10.1080/07294360.2014.934336

Blissenden, M., \& Newlyn, D. (2012). Tax law teaching : the move from traditional models of curriculum to productive authentic forms. Journal of the Australasian Law Teachers Association, 5(1), 1-10.

Brady, L., \& Kennedy, K. (2003). Curriculum construction (2nd ed.). Sydney: Pearson Education.

Brutus, S., \& Donia, M. B. L. (2010). Improving the effectiveness of students in groups with a centralized peer evaluation system. Academy of Management Learning \& Education, 9(4), 652-662. https://doi.org/10.5465/AMLE.2010.56659882

Chetty, R.., \& Saez, E. (2013). Teaching the tax code: Earnings responses to an experiment with eltc recipients. American Economic Journal: Applied Economics, 5(1), 1-31. https://doi.org/10.1257/app.5.1.1

Costa, A. L., \& Kallick, B. (2000). Integrating and sustaining habits of mind. Melbourne, VIC: Hawker Brownlow Education.

Creswell, J. W. (2013). Educational research: Planning, conducting and evaluating quantitative and qualitative research. Essex: Pearson.

De Bono, E. (1985). Six thinking hats. England: Penguin Books.

De Bono, E. (1992a). Six thinking hats for schools: Resource Book 1. Melbourne, VIC: Hawker Brownlow Education.

De Bono, E. (1992b). Six thinking hats for schools: Resource Book 2. Melbourne, VIC: Hawker Brownlow Education.

De Bono, E. (1992c). Six thinking hats for schools: Resource Book 3. Melbourne, VIC: Hawker Brownlow Education.

De Bono, E. (1992d). Six thinking hats for schools: Resource Book 4. Melbourne, VIC: Hawker Brownlow Education.

De Bono, E. (1995). Serious creativity. The Journal for Quality and Participation, 18, 12-18. 
Eldeen, A. S. M., \& Maher, A. E. (2016). The effect of the six thinking hats strategy in teaching health and fitness course on the development of creative thinking and the academic achievement level. Science, Movement and Health, 16(2), 209-215.

Esterberg, K. G. (2002). Qualitative methods in social research. Boston: McGraw- Hill.

Evin Gencel, I. (2017). The effect of portfolio assessments on metacognitive skills and on attitudes toward a course. Educational Sciences: Theory \& Practice, 17(1), 5-31.

Facione, P. A. (2011). Measured reasons and critical thinking. Lillbrae, CA: The California Academic Press.

Geissler, G. L., Edison, S. W., \& Wayland, J. P. (2012). Improving students' critical thinking, Creativity, and communication skills. Journal of Instructional Pedagogies, 8, 1-11.

Graeff, T. R. (2010). Strategic teaching for active learning. Marketing Education Review, 20(3), $265-278$.

Gudmunson, C. G., Zuiker, V. S., Katrsa, M. J., \& Sabri, M. F. (2015). Enhancing personal and family finance courses using case studies. College Student Journal, 49(3), 321-330.

Hodge, E. M., \& Ozag, D. (2007). The relationship between North Carolina teachers' trust and hope and their organizational commitment. Delta Pi Epsilon Journal, 49(2), 128-139.

Huxham, M. (2005). Learning in lectures: Do 'interactive windows' help? Active Learning in Higher Education, 6 (1), 17-31. https://doi.org/10.1177/1469787405049943

Kivunja, C. (2015a). Teaching, learning and assessment: Steps towards creative practice. Melbourne: Oxford University Press.

Kivunja, C. (2015b). Exploring the pedagogical meaning and implications of the 4cs 'super skills' for the $21 \mathrm{st}$ century through Bruner's 5e lenses of knowledge construction to improve pedagogies of the new learning paradigm. International Journal of Creative Education, 6, 224-239. https://doi.org/10.4236/ce.2015.62021

Kivunja, C. (2015c). Using De Bono's six thinking hats model to teach critical thinking and problem solving skills essential for success in the 21st century economy. Creative Education, 6, 380-391. https://doi.org/10.4236/ce.2015.63037

Kuh, G. D., Kinzie, J., Schuh, J. H., \& Whitt, E. J. (2010). Student success in college: Creating conditions that matter. San Francisco, CA: American Association for Higher Education.

Maurer, T. W., \& Lee, S. (2011). Financial education with college students: comparing peer-led and traditional classroom instruction. Journal of Family and Economic, 32 , 680-689. https://doi.org/10.1007/s10834-011-9266-Z

McCullough, K., \& Munro, N. (2016). Finance students' experiences of lecture-based active learning tasks. Innovations in Education and Teaching International, 53(1), 1-9.

Miglictti, C. (2002). Using Ccoperative small groups in introductory accounting classes: a practical approach. Journal of Education for Business, 78(2), 111-115. https://doi.org/10.1080/08832320209599707

Miles, M. B., \& Huberman, A. M. (1994). Qualitative data analysis (2nd ed.). Thousand Oaks, CA: Sage Publications.

O’Prey, L., \& Shephard, D. (2014). Financial education for children and youth: a systematic review and meta-analysis. Aflatoun Working Paper. Retrieved from Academia.edu

Petty, G. (2009). Teaching today: A practical guide. Cheltenham: Nelson Thornes Ltd.

Reiter-Palman, R., \& Robinson, E. J. (2009). Problem identification and construction: Examining the relationship between naive dialectical thinking, ethnicity, and creativity. Creativity Research Journal, 21(2), 1-13.

Schellens, T., Van Keer, H., De Wever, B., \& Valcke, M. (2009). Tagging thinking types in asynchronous discussion groups: Effects on critical thinking. Interactive Learning Environment, 17(1), 77-94.

Tapscott, D. (2009). Grown up digital: How the net generation is changing your world. New York: McGraw-Hill.

Vernon, D., \& Hocking, I. (2014). Thinking hats and good men: Structured techniques in a problem construction task. Thinking Skills and Creativity, 14, 41-46. https://doi.org/10.1016/j.tsc.2014.07.001

Wooldridge, B. R. (2008). Golden duck awards: An interactive game to facilitate class participation. Marketing Education Review, 18, 15-17. https://doi.org/10.1080/10528008.2008.11489019 